Am J Psychiatry Vol. 162(9):1628-1636 (2005)

ISSN: (print 0002-953X)(online 1535-7228)

doi: 10.1176/appi.ajp.162.9.1628

This is a peer-reviewed pre-print version of the following article: Cost-Effectiveness of ADHD Treatments:

Findings From the Multimodal Treatment Study of Children With ADHD, which has been published in final form

at:

http://www.appi.org

http://www.appi.org/SearchCenter/Pages/Journal.aspx?ItemId=AJP

http://ajp.psychiatryonline.org/article.aspx?articleid=177754

(C) 2005 American Psychiatric Publishing, Inc.

\title{
Cost-Effectiveness of ADHD Treatments: Findings From the Multimodal Treatment Study of Children With ADHD
}

\author{
Peter S. Jensen, M.D., Joe Albert Garcia, Ph.D., Sherry Glied, Ph.D., Maura Crowe, B.A., \\ Mike Foster, Ph.D., Michael Schlander, M.D., M.B.A., Stephen Hinshaw, Ph.D., \\ Benedetto Vitiello, M.D., L. Eugene Arnold, M.D., Glen Elliott, M.D., Lily Hechtman, \\ M.D., Jeffrey H. Newcorn, M.D., William E. Pelham, Ph.D., James Swanson, Ph.D., \\ Karen Wells, Ph.D.
}

Abstract

Objective: Attention deficit hyperactivity disorder (ADHD) is a costly public health problem. To the authors' knowledge, this is the first study on the cost-effectiveness of the major forms of ADHD treatments used in NIMH's Multimodal Treatment Study of Children With ADHD (MTA Study).

Method: Five hundred seventy-nine children with ADHD, combined type, ages 7 to 9.9, were assigned to 14 months of medication management, behavioral treatment, both combined, or community care. Services were tallied throughout the study, including medication, health care visits, behavioral treatments, and rental costs. Provider specialty, total time, and number of visits with providers were used to calculate costs, adjusted to FY 2000 dollars with the consumer price index.

Results: Treatment costs varied fourfold, with medication management being the least expensive, followed by behavioral treatment, and then combined treatment. Lower costs of medication treatment were found in the community care group, reflecting the less intensive (and less effective) nature of community-delivered treatment. Medical management was more effective but more costly than community care and more cost-effective than combination treatment and behavioral treatment alone. Under some conditions, combination treatment (medical management and psychotherapy) were somewhat more cost-effective, as demonstrated by lower costs per additional child "normalized" among children with multiple comorbid disorders.

Conclusions: Medical management treatment, although not as effective as combined medical management and behavioral treatment, is likely to be more cost-effective in routine treatment for children with ADHD, particularly those without comorbid disorders. For some children with comorbid disorders, it may be cost-effective to provide combination treatment.

Attention deficit hyperactivity disorder (ADHD) is the most prevalent behavioral disorder in children (1) and represents a costly major public health problem. Without effective treatments, difficulties experienced by children with ADHD may continue or even increase into adulthood, resulting in possible justice system contacts and substance abuse troubles (2), as well as effects on ultimate rates of child abuse, crime, adult mental illness, and accidents with severe injuries (3, 4). Although use and treatment rates are increasing, little is known about the cost of these treatments and services for children or the overall financial impact on society (2). Economic studies of mental health services are rare in the literature and are especially scarce for specific children's disorders, such as ADHD (3).

In a study specifically related to ADHD, Kelleher et al. (5) examined the costs of this disorder within a Medicaid population, finding that pharmaceutical costs were $42 \%$ higher for 
children with ADHD than for those with a similarly prevalent comparison condition-asthma. Similarly, in the first study to provide national estimates, Chan et al. (6) found that the differences in costs between ADHD and asthma were statistically significant only for prescription-related costs and out-of-pocket expenses, with ADHD incurring higher costs. Swensen and colleagues (7) studied the resource use of insured patients with ADHD and their family members and found that the average annual medical costs per family member were approximately double for ADHD families compared to matched comparison families $(\$ 2,461$ versus $\$ 1,220$, respectively). Also, costs for the family member with ADHD were three times higher than those for comparison subjects (\$2,128 versus \$741). Notably, only $13 \%$ of the costs for patients with ADHD were attributable to treatment of the disorder, possibly because most of them were not regularly receiving treatment.

In examining the health care records of nearly 5,000 children over a 9-year period, Leibson et al. (8) noted the difference in health care use and costs between children with and without ADHD. Cost analyses indicated that all types of medical bills were higher for children with ADHD in all of the 9 years. The median costs for children with ADHD were more than double those without ADHD (\$4,306 versus \$1,944).

The presence of an accompanying clinical diagnosis (in addition to ADHD) can exert substantial effects on the cost of treatment. For example, Guevara et al. (9) compared the health care costs and use between children with and without ADHD in a retrospective matched cohort study. Approximately 30\% of all children with ADHD in their study were diagnosed with a coexisting mental health disorder. This comorbidity entailed additional costs of \$437 per child (\$812 versus \$375) for total health care services in comparison to the children with ADHD but no comorbidity. This effect of comorbidity on costs is common throughout the literature (10) and may denote the need for differential treatments to reduce expenses and reach better treatment outcomes. Although these studies illuminate the burden of illness associated with ADHD, no studies, to our knowledge, have addressed the cost and cost-effectiveness of specific treatments for ADHD in the United States.

International analyses have been rare, too. In a report commissioned by the Canadian Coordinating Office for Health Technology Assessment, Miller et al. (11) compared six treatments: methylphenidate, dexamphetamine, pemoline (high-dose and low-dose), nondrug therapy, combined therapy, and no treatment, adopting a 1-year time horizon and the perspective of third-party payers. Based on a systematic review of the literature (12), treatment effects were determined by the Conners' Teachers Rating Scale. The methylphenidate strategy was found to dominate its alternatives, with a cost of $\$ 498$ (Canadian) per 6-point (or one standard deviation) improvement in score on the Conners' Teachers Rating Scale. It should be noted here that effectiveness data for the psychological/ behavioral (nondrug) and the combination strategies were based on fewer than 20 patients each, resulting in widely associated 95\% confidence intervals, translating into corresponding uncertainty of the economic evaluation presented. In the United Kingdom, Gilmore and Milne (13) found, from the perspective of the National Health Service, that methylphenidate was cost-effective in children with hyperkinetic disorder, according to ICD-10 criteria. This study considered neither behavioral nor combined treatment strategies, however. Regardless, although international studies are interesting, their cost-effectiveness data cannot be assumed to be applicable to the United States health care context, what has been called the "portability problem" (14).

The most comprehensive ADHD treatment study to date is the six-site National Institute of Mental Health Multimodal Treatment Study of Children With ADHD (MTA Study), a 
randomized, controlled study of 579 children designed to examine the intermediate and long-term effectiveness of treatment options for $\operatorname{ADHD}(15,16)$. The results indicated that for ADHD symptoms, children in the combined treatment or medication management groups showed significantly greater improvement than those given community care or behavioral treatment alone $(15,16)$. For children with comorbid ADHD, better outcomes were achieved through different treatment options, depending on the type of comorbidity (17). Thus, the MTA Study offers an excellent opportunity to examine the cost-effectiveness of different treatment modalities for children with ADHD — with and without various comorbid disorders.

\section{Method}

\section{Study Design, Procedures, Subjects, and Treatments}

Five hundred seventy-nine children with ADHD, combined type, ages 7 to 9.9 years, were assigned to 14 months of medication management (titration followed by monthly half-hour visits), intensive behavioral treatment (parent, school, and child components, with therapist involvement gradually reduced over time), the two combined, or routine community care (treatments by community providers). Outcomes were assessed in multiple domains before, during, and at treatment endpoint (with combined treatment and medication management groups continuing medication at all assessment points) (18). Data were analyzed with intent-to-treat, random effects regression.

\section{Initial MTA Study Results}

All four groups showed sizable reductions in symptoms over time, with significant differences among them in degrees of change $(15,16)$. For ADHD symptoms, the groups receiving combined medical management and behavioral treatment and medical management improved significantly more than those with behavioral treatment or community care. Combined medical management and behavioral treatment and medical management did not differ significantly on direct comparisons in primary analyses, but in several instances (oppositional/aggressive symptoms, internalizing symptoms, teacher-rated social skills, parent-child relations, and reading achievement), combined medical management and behavioral treatment proved superior to behavioral treatment and/or community care, whereas medical management did not. The MTA Study's intensive medication strategy (combined medical management and behavioral treatment/medical management) was superior to community care, despite the fact that two-thirds of community-treated subjects received similar medication during the study.

\section{Measures}

The MTA Study used a comprehensive battery of tests, drawing upon multiple informants across multiple outcome domains, as previously described (15). For the purposes of the analyses presented here, we used a composite outcome measure of treatment success to examine the study's clinical relevance and practical significance (19). Thus, the end-of-treatment status of each subject was evaluated based on a combined overall rating, completed by both parents and teachers, of DSM-IV symptoms of ADHD and oppositional defiant disorder, using the SNAP scale, developed by Swanson and colleagues $(19,20)$. This instrument allowed parents and teachers to score each symptom on a scale with ratings of from 0 (none), 1 (just a little), 2 (moderate), and 3 (a lot). All items were tallied and then divided by the mean number of items to 
yield an average item response, and then parent and teacher scores were combined. A low overall symptom severity rating (less than 1 or from "none" up to "just a little") was found by receiver operating characteristic analyses to constitute a reliable criterion for treatment success. Logistic regression analyses were used to compare success rates for the treatments. The results showed that the success rates for MTA Study treatments mirrored the primary results, with the following proportions of children being "normalized" in each of the groups: combined medical management and behavioral treatment $=68 \%$, medical management $=56 \%$, behavioral treatment $=34 \%$, and community care $=25 \%$. Note that all such differences were statistically significant; that is, each treatment group differed significantly from all others in terms of rates of treatment success. Based on ratings of children drawn from the same classrooms, $88 \%$ of classroom comparison children scored in this relatively nonsymptomatic range, whereas none of the MTA Study children scored in this range before random assignment. We used this dichotomized "treatment success" variable as our outcome criterion for cost-effectiveness analyses.

The revised Services for Children and Adolescents-Parent Interview $(21,22)$ was used by research staff to assess the use of mental health services across multiple service systems for all four treatment groups. This measure was given at 3-month intervals during treatment and 3-6-month intervals after treatment, and we asked the families to report on the use of any medical and school services, community mental health services, or juvenile justice services. This allowed us to determine the amount and type of services used, the medication costs, and the costs associated with primary care versus specialty mental health services across all four randomly assigned groups. The reliability and validity of this scale are excellent (21, 22).

\section{Costs}

The societal perspective (excluding possible time lost from work by parents) was used to determine the costs for this study, as suggested by the Panel on Cost-Effectiveness in Health and Medicine (23). Thus, all of the direct costs associated with providing each of the treatment arms were calculated by using the real treatment costs of the MTA Study, while excluding costs associated with the research component of the study, such as research staff time and costs associated with administering the study instruments. The costs were calculated whether they might be paid by a patient, an insurer, or any other third party. All the costs associated with a given service were assumed to be the same across sites, despite the regional differences in the cost of living or in actual billing charges for a specific service. All costs were adjusted for inflation to year 2000 dollars by using the consumer price index to ensure that the results of the study could be understood in terms of current dollar amounts.

Costs of the medications were calculated by using information from the National Data Drug File Plus (http://wwwfirstdatabank. com/knowledge_bases/nddf_plus). This database allows for a sampling of the average wholesale prices of all drugs from various pharmaceutical companies and in varying pill sizes. For example, Ritalin can be priced from either Novartis Pharmaceuticals or Physicians Total Care for the 5-mg, 10-mg, and 20-mg pill sizes. These wholesale prices present different prices per milligram; therefore, a median price was chosen for each medication. The following prices were used for each medication: Ritalin, Novartis, 10-mg

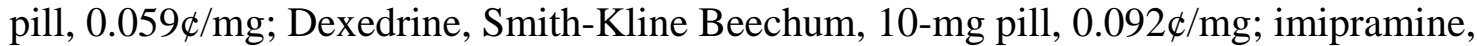
Allscripts, 50-mg pill, 0.013థ/mg; Cylert, Abbott Pharmaceutical, 37.5-mg pill, 0.046 $\$$ /mg; and bupropion, Geneva, 100-mg pill, 0.009 $\$ / \mathrm{mg}$.

The costs of the psychiatrist, psychologist, pediatrician, teacher, and teachers' aide times 
were calculated by determining an hourly wage for these professionals based on their respective annual salaries. The adjusted yearly salary of the psychiatrists by using the consumer price index, was determined to be $\$ 142,919.80$, based on data from the American Medical Association's Socioeconomic Monitoring System survey (24). This salary was selected as a conservative estimate, given that it is within the range of pediatrician and average physician salaries. Psychologist-adjusted salaries were calculated as \$80,523.24, based on Scheffler et al. (25). Teacher salaries (for those who worked in the summer treatment program) and teachers' aide salaries were determined by the Bureau of Labor Statistics (26). Appropriate levels of fringe benefits were added to the salaries to capture total compensation. (For teachers' aides, a rate of $23.5 \%$ was used; for psychologists and psychiatrists, we used a rate of $27.4 \%$. These figures were derived from data from the Bureau of Labor Statistics [26].) Finally, the cost of attending each day of the summer treatment program was calculated by using the hourly wages of the staff needed for the program.

\section{Cost-Effectiveness}

Thus, each treatment had both a cost and an outcome associated with it, with cost-effectiveness comprising the average total cost per child per unit of outcome (i.e., per child "normalized") in each of the four groups. A measure of cost-effectiveness is the marginal or incremental cost-effectiveness ratio. This ratio represents the difference in the average cost divided by the difference in average effectiveness:

$$
\frac{\overline{\mathrm{C}}_{\text {NewTx }}-\overline{\mathrm{C}}_{\text {UsualTx }}}{\overline{\mathrm{E}}_{\text {NewTX }}-\overline{\mathrm{E}}_{\text {UsualTx }}}
$$

This ratio represents the (incremental) cost of the new treatment for each unit of additional outcome. When comparing two treatments, a negative cost-effectiveness ratio means that one treatment costs more and is less effective than its comparison treatment. In this case, one treatment "dominates" the other. These figures are rarely reported because one would presumably never choose this treatment.

As suggested by Kaplan and Groessl (27), for cost-effectiveness studies, sensitivity analysis can be conducted to determine if overall cost-effectiveness findings would have varied appreciably had one made different assumptions concerning any uncertain and/or influential cost estimates. For these purposes, we conducted two additional analyses. One was conducted with a lower estimate of psychologist salaries that allowed us to make a more conservative (lower-priced) estimate for psychosocial service costs by using the lowest costs in each category versus more expensive estimates of psychosocial service costs. The other analysis used a higher estimate of the cost of medications, with approximate retail prices instead of the more typically used wholesale prices.

\section{Comorbidity Subgroups}

Given previous evidence that the presence of a comorbid disorder can exert a substantial effect on costs and that MTA Study subjects showed differential treatment effects as a function of comorbidity patterns (17), children were categorized into one of four comorbidity profiles by using our previously employed grouping strategy: ADHD only (31.8\%, N=184), ADHD plus internalizing comorbid disorder only (anxiety or depression) $(14.0 \%, \mathrm{~N}=81)$, ADHD plus externalizing comorbid disorder only (conduct or oppositional defiant disorder) (29.5\%, $\mathrm{N}=171$ ), and ADHD plus both types of comorbid disorder (24.7\%, $\mathrm{N}=143)$. Costs and cost-effectiveness 
of each treatment arm were computed both for the overall MTA Study sample and for these specific comorbidity groups. Note that it was not expected that the costs in the three MTA Study treatment groups would vary because treatment was established and limited by protocol. However, the effectiveness for each treatment varied as a function of comorbidity, as reported previously (17) and shown here in Table 1 in terms of the proportion of children "normalized" by each treatment for each of the comorbidity profiles. As seen in Table 1, the costs for the comorbidity subgroups in the community care group varied, presumably since families appear to have used different services as a function of their children's comorbidity profiles.

\section{Results}

\section{Costs}

Table 2 shows the costs for each treatment group and demonstrates how the costs broke down for each of the categories of treatment. The total cost of treatment ranged from \$1,071 for community-treated subjects to $\$ 7,827$ for

\begin{tabular}{|c|c|c|c|c|c|c|c|c|}
\hline \multirow[b]{2}{*}{ Group } & \multicolumn{2}{|c|}{$\begin{array}{c}\text { Medical } \\
\text { Management }\end{array}$} & \multicolumn{2}{|c|}{$\begin{array}{l}\text { Intensive } \\
\text { Behavioral } \\
\text { Treatment }\end{array}$} & \multicolumn{2}{|c|}{$\begin{array}{l}\text { Combined Medical } \\
\text { Management and } \\
\text { Behavioral Treatment }\end{array}$} & \multicolumn{2}{|c|}{$\begin{array}{c}\text { Routine } \\
\text { Community Care }\end{array}$} \\
\hline & $\mathrm{N}$ & $\%$ & $\mathrm{~N}$ & $\%$ & $\mathrm{~N}$ & $\%$ & $\mathrm{~N}$ & $\%$ \\
\hline All children $(\mathrm{N}=579)$ & 144 & 56 & 144 & 34 & 145 & 68 & 146 & 25 \\
\hline $\begin{array}{l}\text { Children with ADHD only } \\
\text { Children with comorbid } \\
\text { disorders }\end{array}$ & 46 & 57 & 43 & 42 & 53 & 70 & 42 & 31 \\
\hline ADHD plus internalizing & 20 & 80 & 23 & 39 & 19 & 74 & 19 & 21 \\
\hline $\begin{array}{l}\text { ADHD plus externalizing } \\
\text { disorder }\end{array}$ & 40 & 58 & 42 & 19 & 36 & 67 & 54 & 28 \\
\hline $\begin{array}{l}\text { ADHD plus both types of } \\
\text { disorder }\end{array}$ & 38 & 39 & 36 & 39 & 37 & 62 & 31 & 16 \\
\hline
\end{tabular}

TABLE 1. “Normalization” Rates by Comorbidity Subgroup for Children With Attention Deficit Hyperactivity Disorder (ADHD)

combined medical management and behavioral treatment subjects, with the bulk of combined medical management and behavioral treatment costs $(\$ 6,881)$ due to the behavioral treatment components. Pairwise comparisons showed that each treatment cost was significantly different from all others at the 0.05 level.

In Table 3, the costs are shown for each of the four comorbidity profiles by treatment arm. The costs for the internalizing-only children, the externalizing-only children, and the children with both types of comorbid disorder in the medication-only group varied little, presumably because of the highly structured nature of the treatment protocol. Note that treatment costs for children in community care with conduct disorder/oppositional defiant disorder and both types of comorbid disorders were substantially higher (\$1,204 and \$976, respectively) than the costs for internalizing children (\$718), possibly because of the increased treatment needs among externalizing subjects, which for these participants were handled ad libitum by families and their health care providers. Within each treatment group, none of these costs were significantly different from each other, however.

Table 4 shows several incremental cost-effectiveness ratios comparing each of the 
different treatment arms, which were then broken down by comorbidity. The incremental cost-effectiveness ratio for medical management versus community care was \$360, indicating that it cost that amount for each of the children brought to normal functioning by treating them through medication management, and they would not have been brought to normal functioning by treating them through usual care in the community. The cost-effectiveness ratio for behavioral treatment versus community care was $\$ 68,128$, demonstrating a large increase in the cost to bring a child to normal functioning by treating him or her with psychosocial interventions. The combined cost-effectiveness ratio of medical management and behavioral treatment to

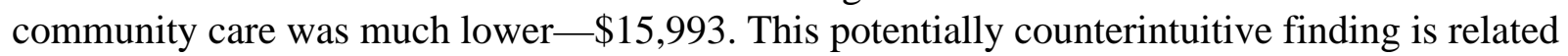
to the fact that although combined medical management and behavioral treatment was the most expensive treatment, such cost was largely offset by the increase in effectiveness achieved through the medication component of this multimodal intervention.

The combined medical management and behavioral treatment/medical management cost-effectiveness ratio was $\$ 55,253$. That is, there was a large increase in price (or a sharp decrease in cost-effectiveness) related to adding behavioral intervention to medication management. The incremental cost-effectiveness ratio between the combined medical management and behavioral treatment and behavioral treatment alone was $\$ 2,500$. Finally, the comparison between behavioral treatment and medical management showed a negative incremental cost-effectiveness ratio. In this case, the negative number indicates that the medication condition was both less expensive and more effective, leaving the "dominant" treatment remaining as the logical choice in this circumstance.

The interior columns of Table 4 show the cost-effectiveness ratios for the same comparisons just mentioned but subcategorized by comorbidity. For the ADHD-only group, the cost-effectiveness ratios were in the same order as the previous ones. Likewise, for the ADHD group with internalizing difficulties, the cost-effectiveness ratios were in the same order but with a negative ratio for the comparison between combined medical management and behavioral treatment versus medical management. This was because medical management was slightly more effective than combined medical management and behavioral treatment, whereas combined medical management and behavioral treatment costs more, resulting in a negative ratio. The ADHD-plus-externalizing group also had a negative ratio for the behavioral treatment versus community care comparison, again because behavioral treatment costs more, whereas community care was slightly more effective numerically. We did not report computed negative ratios. In most of these cases, one treatment was both more costly and less effective than the alternative. Presumably, one would never choose a less effective, more expensive treatment over another. In the case of the other ratios, the monetary values reported gave the relative expenses of choosing one treatment over another, and it remains a decision by policy makers, patients, or administrators to decide how much is an acceptable level of cost to incremental benefit.

Figure 1 illustrates the relationships among the four treatment groups, with outcomes portrayed on the vertical axis and costs on the horizontal axis. Treatment as usual (community care) is represented as the origin, and so the slope of the lines linking the origin to each point represents the incremental cost-effectiveness ratio for that treatment.

\begin{tabular}{|c|c|c|c|c|}
\hline \multirow[b]{3}{*}{ Variable } & \multicolumn{4}{|c|}{ Cost per Child per Treatment Arm (\$) } \\
\hline & Medical & $\begin{array}{l}\text { Intensive } \\
\text { Behavioral }\end{array}$ & $\begin{array}{l}\text { Combined Medical } \\
\text { Management and }\end{array}$ & Routine \\
\hline & Management & Treatment & Behavioral Treatment & Community Care \\
\hline
\end{tabular}




\begin{tabular}{lrrrr}
\hline Total & 1,180 & 6,988 & 7,827 & 1,071 \\
Components of cost & & & & \\
$\quad$ Medication & 624 & 104 & 538 & 222 \\
Medication visit & 393 & 34 & 408 & 91 \\
Psychosocial therapy & 163 & 6,850 & 6,881 & 757 \\
\hline
\end{tabular}

TABLE 2. Cost per Child per Treatment Arm (\$) for Children With Attention Deficit Hyperactivity Disorder (ADHD) During 14 Months of Treatment

\begin{tabular}{lcccc}
\hline & \multicolumn{4}{c}{ Cost per Child per Treatment Arm (\$) } \\
\cline { 2 - 5 } Child Diagnosis & $\begin{array}{c}\text { Medical } \\
\text { Management }\end{array}$ & $\begin{array}{c}\text { Intensive Behavioral } \\
\text { Treatment }\end{array}$ & $\begin{array}{c}\text { Combined Medical } \\
\text { Management and } \\
\text { Behavioral Treatment }\end{array}$ & $\begin{array}{c}\text { Routine } \\
\text { Community Care }\end{array}$ \\
\hline $\begin{array}{l}\text { ADHD only } \\
\begin{array}{l}\text { ADHD plus internalizing } \\
\text { disorder }\end{array}\end{array}$ & 1,079 & 7,176 & 7,438 & 1,131 \\
$\begin{array}{l}\text { ADHD plus externalizing } \\
\text { disorder }\end{array}$ & 1,231 & 6,447 & 8,138 & 718 \\
$\begin{array}{l}\text { ADHD plus both types of } \\
\text { disorder }\end{array}$ & 1,245 & 7,080 & 8,083 & 1,204 \\
\hline
\end{tabular}

TABLE 3. Cost per Child per Treatment Arm (\$) by Comorbidity Subgroup for Children With Attention Deficit Hyperactivity Disorder (ADHD) During 14 Months of Treatment

\section{Statistical Significance}

Each point estimate on Figure 1 is surrounded by a "cloud" of points. These reflect the fact that the mean cost and effects for each treatment are an estimate and are subject to sampling error. The additional points were generated by using bootstrapping and capture the uncertainty surrounding each estimate. One can see that the differences in the three treatments offered represent more than sampling error and that the incremental cost-effectiveness ratios for each can be meaningfully distinguished. This finding is confirmed by confidence intervals for each of the incremental cost-effectiveness ratios (available from the first author). These intervals generally indicate that the analyses were sufficiently powered.

\section{Sensitivity Analysis}

There was uncertainty in some of the assumptions involved in estimating the costs of behavioral treatment. For example, we had widely varying estimates of psychologist salaries, depending upon the source: the Bureau of Labor Statistics reported that psychologist salaries are a mean of $\$ 45,000$, quite different from that $(\$ 80,000)$ found in other sources $(25)$. By using this lower estimate for salary instead, we arrived at a more conservative estimate of the cost of some of the psychosocial components. However, this did not change the cost-effectiveness ratios significantly. When we reexamined Table 4 costs, these analyses revealed that there was a $\$ 1,178$ decrease in the cost-effectiveness ratio when we compared combined medical management and behavioral treatment to community care, an \$861 increase in medical management compared to community care, a \$5,539 decrease in the comparison of behavioral treatment to community care, and a \$6,298 decrease in the comparison of the cost-effectiveness ratio for combined medical management and behavioral treatment to medical management group (data available upon request from the first author). These ratios represent the psychosocial costs at their lowest estimates but did not appreciably change the findings presented earlier. 
The second sensitivity analysis used retail prices for medications instead of wholesale prices. The marked-up retail prices were estimated at $40 \%$ higher than wholesale prices, as estimated by Danzon (28). Of interest, this analysis also did not change the cost-effectiveness ratios considerably, except in the comparison between medical management and community care. When we looked again at Table 4 costs for reference, the comparison of medical management to community care showed a \$532 increase, which more than doubled the cost-effectiveness ratio but still showed a relatively cost-effective alternative treatment for medical management versus behavioral treatment and combined medical management and behavioral treatment. The other ratios showed similar patterns as the original analysis, with the cost-effectiveness ratio for behavioral treatment to community care at $\$ 67,683$, combined medical management and behavioral treatment to community care at $\$ 16,314$, combined medical management and behavioral treatment to medical management at $\$ 55,043$, combined medical management and behavioral treatment to behavioral treatment at $\$ 3,019$, and behavioral treatment to medical management still showing medical management as a dominant treatment.

\section{Discussion}

Our findings suggest that the ADHD treatment costs of medication, behavioral treatment, and combined therapies are within the range of costs for many other chronic illnesses $(5,6)$, although within these three treatments, fourfold

Cost-Effectiveness Estimate per Child (\$)

\begin{tabular}{|c|c|c|c|c|c|}
\hline Treatment & Total & $\begin{array}{l}\text { ADHD } \\
\text { Only }\end{array}$ & $\begin{array}{c}\text { ADHD Plus } \\
\text { Internalizing } \\
\text { Disorder } \\
\end{array}$ & $\begin{array}{c}\text { ADHD Plus } \\
\text { Externalizing } \\
\text { Disorder }\end{array}$ & $\begin{array}{c}\text { ADHD Plus } \\
\text { Both Types of } \\
\text { Disorder } \\
\end{array}$ \\
\hline Medical management versus community & 360 & $-^{\mathrm{a}}$ & 870 & 140 & 988 \\
\hline $\begin{array}{l}\text { Intensive behavioral treatment versus } \\
\text { community care }\end{array}$ & 68,128 & 55,418 & 31,690 & & 26,480 \\
\hline $\begin{array}{l}\text { Combined medical management and } \\
\text { behavioral treatment versus community }\end{array}$ & 15,993 & 16,230 & 14,099 & 17,691 & 15,208 \\
\hline $\begin{array}{l}\text { Combined medical management and } \\
\text { medical management }\end{array}$ & 55,253 & 47,844 & $-^{\mathrm{b}}$ & 74,597 & 29,840 \\
\hline $\begin{array}{l}\text { Combined medical management and } \\
\text { intensive behavioral treatment }\end{array}$ & 2,500 & 936 & 4,896 & 2,106 & 4,184 \\
\hline Intensive behavioral treatment versus & $-\mathrm{b}$ & $-{ }^{b}$ & $-\mathrm{b}$ & $-\mathrm{b}$ & $-{ }^{\mathrm{b}}$ \\
\hline
\end{tabular}

a Medical management "dominated" community care in the "ADHD Only” subgroup, i.e., it was less expensive and more effective.

${ }^{\mathrm{b}}$ The absence of numbers indicates that one treatment was both more expensive and less effective, making it an untenable choice for a treatment of this duration.

TABLE 4. Cost-Effectiveness Estimates per Child (\$) by Comorbidity Subgroup for Children With Attention Deficit Hyperactivity Disorder (ADHD) During 14 Months of Treatment

variations were seen. Medical management (the costs of both medication and physician visits) was the least expensive $(\$ 1,180)$, followed by behavioral treatment $(\$ 6,988)$, at over five times the cost of medication, and combined medical management and behavioral treatment $(\$ 7,827)$, at over six times the cost of medication alone.

As one would expect, within the three MTA Study treatment arms, the cost of the medical management treatment component was equivalent to the same medication 
treatment-related costs within the combined medical management and behavioral treatment arms (Table 2). Similarly, the cost of behavioral treatment was the same as the same components within the combined medical management and behavioral treatment arm. This equivalence was as study planners intended, of course, because the combined medical management and behavioral treatment components were based on the same treatments, in type and intensity, as the medical management and behavioral treatment arms. The somewhat lower cost (\$86) of medication in the combined medical management and behavioral treatment arm versus the medical management group reflects the fact that the condition of the subjects in combined medical management and behavioral treatment was maintained with somewhat lower doses of medication than the subjects in medical management, as noted in our first report (15). In contrast, the actual cost for physician visits did not differ between these two arms because the protocol required monthly visits to the physician to monitor the medication. Also of note are the dramatically smaller costs associated with medication treatment in the community care group. Physician visit costs within the community care group were less than one-fourth of the costs of the medical management and combined medical management and behavioral treatment arms, and medication costs were roughly one-third of the cost of the medical management and combined medical management and behavioral treatment arms. Both findings reflect the substantially lower doses used by community physicians for community-treated subjects, as well as the much less frequent monitoring (generally once per month versus two times per year for community care), as noted in our first report (16).

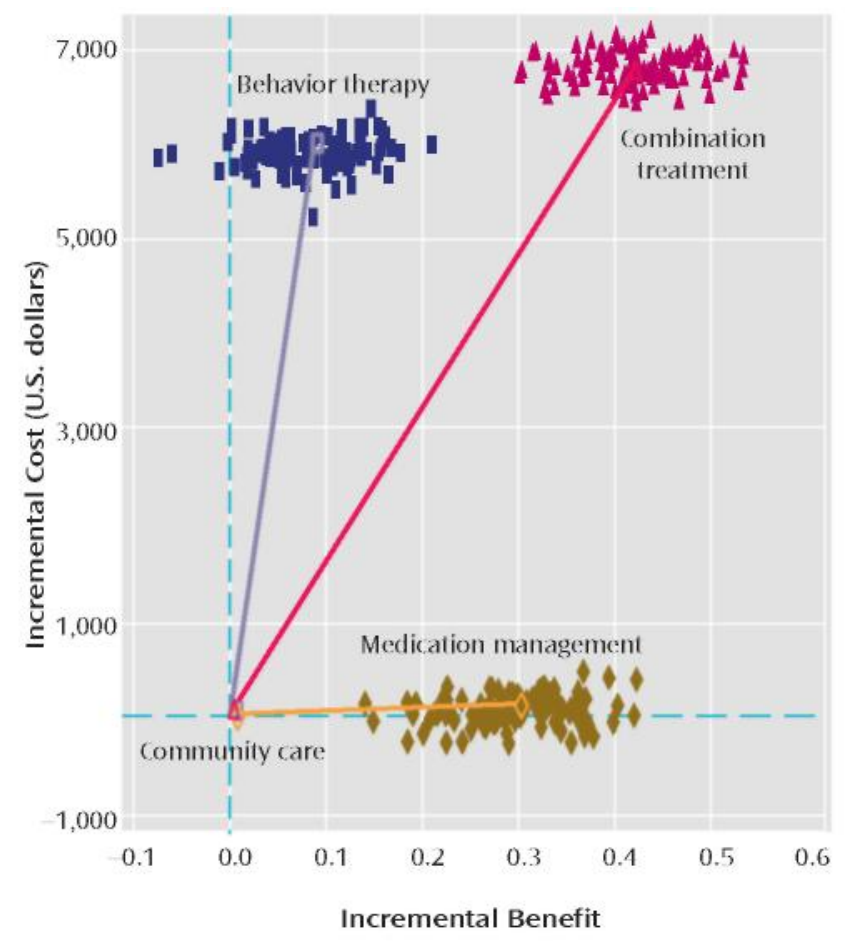

FIGURE 1. Incremental Cost-Effectiveness (\$) of Alternative Treatments Relative to Routine Community Care for Children With Attention Deficit Hyperactivity Disorder (ADHD) During 14 Months of Treatment

As has been previously reported by others, community-treated children with ADHD with certain comorbid disorders do show increased costs for treatment, with the greatest costs seen in children with ADHD plus a disruptive (externalizing) disorder $(\$ 1,204)$ showing an increase over the costs of treating ADHD children with no comorbid disorder $(\$ 1,131)$ and ADHD 
children with an internalizing disorder (depression or anxiety) only (\$718) (Table 3). The costs of community-treated children with both types of comorbid disorder were actually slightly lower (roughly \$230) than for ADHD children with an externalizing disorder. Of note, total costs of care for ADHD children with the various comorbid disorders treated with medical management, behavioral treatment, and combined medical management and behavioral treatment did not differ meaningfully, as one would expect given the structured nature of the MTA Study treatment protocols.

Cost-effectiveness findings comparing the various treatments yielded quite dramatic findings in terms of how much it costs to bring additional children to normal functioning. Under circumstances in which one treatment has been shown to be more effective than another but is also more expensive, the total column in Table 4 shows how much it costs per child to bring additional children to normal functioning with the more effective treatment. Thus, medical management, more effective but also more costly than community care, costs only $\$ 360$ for each of the additional children "normalized" — a fairly modest cost for dramatic gains in the possible number of children effectively treated. However, where only small differences in effectiveness were seen between two treatments, the more intensive, more effective treatment costs much more per additional child "normalized," such as seen in the comparison between combined medical management and behavioral treatment and medical management, with the former costing over $\$ 55,253$ more per additional child “normalized.” Such findings suggest that medication treatment, although as effective as combined medical management and behavioral treatment in terms of overall percentages of children yielding treatment success, might be the more economical alternative in routine treatments for children with ADHD. Other cost-effective comparisons, such as medical management versus behavioral treatment, are not meaningful in cost-effectiveness terms, since medical management is both more effective and less expensive than behavioral treatment (Table 2). These results show medical management to be the “dominant” treatment.

The actual cost differentials vary, however, depending upon the children's comorbidity status, as seen in Table 4. In contrast to the total cost findings, treating children with ADHD plus both types of comorbid disorder with combined medical management and behavioral treatment versus medical management costs somewhat less than previously thought (an incremental cost-effectiveness ratio of $\$ 29,840$ ), suggesting that it is most cost-effective to target combined treatment to children with both types of comorbid disorder. In contrast, combined medical management and behavioral treatment for ADHD children with externalizing comorbid disorder only is not much more effective than medical management alone; thus, costs per additional child "normalized" by using combined medical management and behavioral treatment are far greater (an incremental cost-effectiveness ratio of \$74,597) than the cost of the same treatment for children with ADHD plus both types of comorbid disorder — \$29,840_again, compared to medical management alone.

\section{Limitations}

Of concern is the possibility that some of our cost estimates may be incorrect. In particular, given the implications for the expense of behavioral and combined treatments, we conducted sensitivity analyses examining a range of lower costs associated with behavioral treatment components, as well as adding in the costs of medication treatment for the subset of children in the behavioral treatment group who received medication. These analyses did not yield appreciably different results. In general, where there was uncertainty about cost assumptions, we 
biased our estimates in favor of the behavioral treatment so that behavioral treatment costs could be kept as low as possible. The results, favoring the cost-effectiveness of the medical management condition, were strengthened in light of this bias in favor of the behavioral treatment condition. Of course, it should be noted that the particular psychosocial treatment package was designed within the context of our trial, and other or less intensive behavioral approaches might be more comparable in terms of cost-effectiveness ratios.

Of importance, given our 14-month outcome analyses, our findings did not address the potential longer-term cost-effectiveness of treatment or the broader societal costs incurred as a result of ADHD, such as the condition's impact on parental work absences and loss of income, the costs of special education services and other social services, including the juvenile justice system. Although not examined in the context of this article, they are nonetheless a part of the cost of the illness, if not the cost of treatment.

Finally, it should be noted that, by definition, cost-effectiveness evaluations based on purely clinical outcomes, such as responder rates defined by SNAP scale ratings (19, 20), do not fully address the range of possible comparisons across different types of outcomes. Although our SNAP ratings did have the advantage of being a composite of both parents' and teachers' reports, had we chosen different types of outcomes - such as overall impairment, social skills, or consumer satisfaction—quite different cost-effectiveness ratios may have resulted. Analyses comparing cost-effectiveness ratios across these different types of outcomes will be described in future reports.

Another alternative outcome measure - the cost per number of quality-adjusted life-years gained - has been used widely in health technology assessments because it is commonly believed to enable such comparisons between programs (23). In the absence of direct evidence from the MTA Study on health-related utility weights associated with the treatments investigated, we employed the approach adopted by Lord and Paisley (29) in the United Kingdom, which is very similar to the estimates of Gilmore and Milne (13). Hence, we assume, based on the EQ-5D Quality of Life Scale (30), that without treatment, children would be in health state 11211 (utility weight $=0.883$ ), indicating some difficulties performing their usual activities, and that treatment responders would be returned to full health (health state 11111, with a utility weight of 1.000). These calculations yielded a cost of \$3,077 per quality-adjusted life-year for medical management (over community care) and \$472,248 per quality-adjusted life-year for combined medical management and behavioral treatment (over medical management; \$136,692 if compared with community care only), with intensive behavioral treatment dominated by medical management. These figures provide an estimate of the dimension of the incremental cost per quality-adjusted life-year for the medication management and combined medication management and behavioral treatment strategies.

By way of caution, we note that there is no universally applicable cost-effectiveness benchmark for quality-adjusted life-years. To date, for instance, internationally used thresholds have varied widely, to an extent higher than might be explained by economic variables (31). Furthermore, a review of the willingness-to-pay literature (32) suggests that these thresholds may have been arbitrarily set at levels substantially below those found in value-of-life studies using the contingent-valuation or revealed-preference methods.

For comparative purposes, however, it can be noted that children with ADHD incur similar medical costs as children with asthma $(5,6)$. And in view of the greater costs incurred by ADHD children than healthy children for medical costs (\$1,000-2,000 per year) (7-9) and for auto accidents $(\$ 3,000)(4)$ and their increased use of other expensive programs (special 
education services, juvenile justice, etc.), the modest incremental costs for more effective versus less effective programs (e.g., \$360 for intensive medication management versus standard community care) seem easily justified and potentially a wise investment.

In summary, our findings suggest that carefully monitored medication treatment, although not quite as effective as the combination of medication and behavioral treatment, is likely to be more cost-effective in routine treatments for children with ADHD, particularly those without comorbid disorders. For some children with comorbid disorders, it may be relatively cost-effective to provide combination treatment. By way of caution, it should be noted that although medication management may be the most cost-effective option for achieving treatment success (as defined by symptom improvement) in children, that may not necessarily be the goal of families. For instance, other things may be taken into account, such as side effects, the family's overall feelings about the causes of the disorder in question, and their relative comfort and satisfaction with the treatment approach. These alternative outcome areas will be the subject of future reports.

\section{Acknowledgments}

The Multimodal Treatment Study of Children With ADHD is a cooperative study performed by six independent research teams in collaboration with the staff of the Division of Clinical and Treatment Research of the National Institute of Mental Health (NIMH), Rockville, Md., and the Office of Special Education Programs of the U.S. Department of Education. The NIMH principal collaborators were Peter S. Jensen, M.D., L. Eugene Arnold, M.Ed., M.D., John E. Richters, Ph.D., Joanne B. Severe, M.S., Donald Vereen, M.D., and Benedetto Vitiello, M.D. Principal investigators and co-investigators from the six sites are as follows: University of California at Berkeley/San Francisco (UO1 MH-50461): Stephen P. Hinshaw, Ph.D., Glen R. Elliott, M.D., Ph.D.; Duke University (UO1 MH-50447): C. Keith Conners, Ph.D., Karen C. Wells, Ph.D., John S. March, M.D., M.P.H.; University of California at Irvine/Los Angeles (UO1 MH-50440): James M. Swanson, Ph.D., Dennis P. Cantwell, M.D., Timothy Wigal, Ph.D.; Long Island Jewish Medical Center/Montreal Children's Hospital (UO1 MH-50453): Howard B. Abikoff, Ph.D., Lily Hechtman, M.D.; New York State Psychiatric Institute/Columbia University/Mount Sinai Medical Center (UO1 MH-50454): Laurence L. Greenhill, M.D., Jeffrey H. Newcorn, M.D.; University of Pittsburgh (UO1 MH-50467): William E. Pelham, Ph.D., Betsy Hoza, Ph.D. Helena C. Kraemer, Ph.D. (Stanford University), is a statistical and design consultant. The Office of Special Education Programs/U.S. Department of Education principal collaborator is Ellen Schiller, Ph.D.

\section{References}

1. Richters J, Arnold L, Jensen P, Abikoff H, Conners CK, Greenhill LL, Hechtman L, Hinshaw SP, Pelham WE, Swanson JM: NIMH Collaborative Multisite Multimodal Treatment Study of Children With ADHD, I: background and rationale. J Am Acad Child Adolesc Psychiatry 1995; 34:987-1000

2. National Institutes of Health Consensus Development Conference Statement: Diagnosis and treatment of attention-deficit/ hyperactivity disorder (ADHD). J Am Acad Child Adolesc Psychiatry 1998; 39:182-188

3. Knapp M: Economic evaluations and interventions for children and adolescents with mental health problems. J Child Psychol Psychiatry 1997; 38:3-25

4. Fischer M, Barkley R, Fletcher K, Patel L: Young adult outcomes of childhood ADHD: costs to society, in Scientific Proceedings of the 2001 Annual Meeting of the American Academy of Child and Adolescent Psychiatry. Washington, DC, AACAP, 2001, p 75

5. Kelleher K, Childs G, Harman J: Healthcare costs for children with attention-deficit/hyperactivity disorder. Economics of Neuroscience 2001; 3:60-63

6. Chan E, Zhan C, Homer C: Health care use and costs for children with attention-deficit/hyperactivity disorder. Arch Pediatr Adolesc Med 2002; 156:504-511

7. Swensen A, Birnbaum HG, Secnik K, Marynchenko M, Greenberg P, Claxton A: Attention-deficit/hyperactivity disorder: increased costs for patients and their families. J Am Acad Child Adolesc Psychiatry 2003; 42:1415-1423

8. Leibson C, Katusic S, Barbaresi W, Ransom J, O’Brien P: Use and costs of medical care for children and 
adolescents with and without attention-deficit/hyperactivity disorder. JAMA 2001; 285:60-66

9. Guevara J, Lozano P, Wickizer T, Mell L, Gephart H: Utilization and cost of health care services for children with attention-deficit/hyperactivity disorder. Pediatrics 2001; 108:71-78

10. King R, Gaines L, Lambert E, Summerfelt W, Bickman L: The co-occurrence of psychiatric and substance use diagnoses in adolescents in different service systems: frequency, recognition, cost and outcomes. J Behav Health Serv Res 2000; 27:417-430

11. Miller A, Lee SK, Raina P, Klassen A, Zupancic J, Olsen L: A Review of Therapies for Attention-Deficit/Hyperactivity Disorder. Ottawa, Canadian Coordinating Office for Health Technology Assessment, 1998

12. Klassen A, Miller A, Raina P, Lee SK, Olsen L: Attention-deficit hyperactivity disorder in children and youth: a quantitative systematic review of the efficacy of different management strategies. Can J Psychiatry 1999, 44:1007-1016

13. Gilmore A, Milne P: Methylphenidate in children with hyperactivity: review and cost-utility analysis. Pharmacoepidemiol Drug Saf 2001; 10:85-94

14. Drummond M, Pang F: Transferability of economic evaluation results, in Economic Evaluation in Health Care: Merging Theory With Practice. Edited by Drummond M, McGuire A. Oxford, UK, Oxford University Press, 2001, pp 256-276

15. MTA Cooperative Group: A 14-month randomized clinical trial of treatment strategies for attention-deficit/hyperactivity disorder. Arch Gen Psychiatry 1999; 56:1073-1086

16. MTA Cooperative Group: Moderators and mediators of treatment response for children with attention-deficit/hyperactivity disorder. Arch Gen Psychiatry 1999; 56:1088-1096

17. Jensen P, Hinshaw S, Kraemer H, Lenora N, Newcorn JH, Abikoff HB, March JS, Arnold LE, Cantwell DP, Conners CK, Elliott GR, Greenhill LL, Hechtman L, Hoza B, Pelham WE, Severe JB, Swanson JM, Wells KC, Wigal T, Vitiello B: ADHD comorbidity findings from the MTA Study: comparing comorbid subgroups. J Am Acad Child Adolesc Psychiatry 2001; 40:147-158

18. Hinshaw SP, March JS, Abikoff H, Arnold LE, Cantwell DP, Conners CK, Elliott GR, Halperin J, Greenhill LL, Hechtman LT, Hoza B, Jensen PS, Newcorn JH, McBurnett K, Pelham WE, Richters JE, Severe JB, Schiller E, Swanson J, Vereen D, Wells K, Wigal T: Comprehensive assessment of childhood attention-deficit hyperactivity disorder in the context of a multisite, multimodal clinical trial. J Atten Disord 1997; 1:217-234

19. Swanson J, Kraemer H, Hinshaw S, Arnold LE, Conners CK, Abikoff HB, Clevenger W, Davies M, Elliott GR, Greenhill LL, Hechtman L, Hoza B, Jensen PS, March JS, Newcorn JH, Owens EB, Pelham WE, Schiller E, Severe JB, Simpson S, Vitiello B, Wells K, Wigal T, Wu M: Clinical relevance of the primary findings of the MTA: success rates based on severity of ADHD and ODD symptoms at the end of treatment. J Am Acad Child Adolesc Psychiatry 2001; 40:168-179

20. Swanson J: School-Based Assessments and Interventions for ADD Students. Irvine, Calif, KC Publishing, 1992

21. Jensen PS, Eaton Hoagwood K, Roper M, Arnold LE, Odbert C, Crowe M, Molina BS, Hechtman L, Hinshaw SP, Hoza B, Newcorn J, Swanson J, Wells K: The Services for Children and Adolescents-Parent Interview: development and performance characteristics. J Am Acad Child Adolesc Psychiatry 2004; 43: 1334-1344

22. Eaton Hoagwood K, Jensen PS, Arnold LE, Roper M, Severe J, Odbert C, Molina BS (MTA Cooperative Group): Reliability of the Services for Children and Adolescents-Parent Interview. J Am Acad Child Adolesc Psychiatry 2004; 43:1345-1354

23. Gold MR, Siegel JE, Russell LB, Weinstein MC: Cost-Effectiveness in Health and Medicine. New York, Oxford University Press, 1996

24. AMA Socioeconomic Monitoring System. Chicago, American Medical Association, Center for Health Policy Research, 1999

25. Scheffler R, Ivey S, Garrett A: Changing supply and earning patterns of the mental health workforce. Adm Policy Ment Health 1998; 26:85-99

26. US Department of Labor: Bureau of Labor Statistics, 1999. http:// www.bls.gov

27. Kaplan R, Groessl E: Applications of cost-effectiveness methodologies in behavioral medicine. J Consult Clin Psychol 2002; 70: 482-493

28. Danzon PM: Making sense of drug prices. Regulation 2000; 23: 56-63

29. Lord J, Paisley S: The Clinical Effectiveness and Cost-Effectiveness of Methylphenidate for Hyperactivity in Childhood, Version 2. London, National Institute for Clinical Excellence, August 2000 
30. Rabin R, de Charro F: EQ-5D: a measure of health status from the EuroQol Group. Ann Med 2001; 33:337-343

31. Towse A, Pritchard C, Devlin N (eds): Cost-Effectiveness Thresholds: Economic and Ethical Issues. London, King's Fund and Office of Health Economics, 2002

32. Hirth R, Chernew ME, Miller E, Fendrick AM, Weissert WG: Willingness to pay for quality-adjusted life year: in search of a standard. Med Decis Making 2000; 20:332-342 